\title{
HOXB7 mRNA is overexpressed in pancreatic ductal adenocarcinomas and its knockdown induces cell cycle arrest and apoptosis
}

Thais Chile ${ }^{1}$, Maria Angela Henriques Zanella Fortes ${ }^{1}$, Maria Lúcia Cardillo Corrêa-Giannella', Helena Paula Brentani ${ }^{3}$, Durvanei Augusto Maria ${ }^{4}$, Renato David Puga ${ }^{5}$, Vanessa de Jesus R de Paula ${ }^{6}$, Marcia Saldanha Kubrusly ${ }^{2}$ Estela Maria Novak ${ }^{7,8}$, Telésforo Bacchella ${ }^{2}$ and Ricardo Rodrigues Giorgi ${ }^{*}$

\begin{abstract}
Background: Human homeobox genes encode nuclear proteins that act as transcription factors involved in the control of differentiation and proliferation. Currently, the role of these genes in development and tumor progression has been extensively studied. Recently, increased expression of HOXB7 homeobox gene (HOXB7) in pancreatic ductal adenocarcinomas (PDAC) was shown to correlate with an invasive phenotype, lymph node metastasis and worse survival outcomes, but no influence on cell proliferation or viability was detected. In the present study, the effects arising from the knockdown of HOXB7 in PDAC cell lines was investigated.
\end{abstract}

Methods: Real time quantitative PCR (qRT-PCR) (Taqman) was employed to assess HOXB7 mRNA expression in 29 PDAC, 6 metastatic tissues, 24 peritumoral tissues and two PDAC cell lines. siRNA was used to knockdown HOXB7 mRNA in the cell lines and its consequences on apoptosis rate and cell proliferation were measured by flow cytometry and MTT assay respectively.

Results: Overexpression of HOXB7 mRNA was observed in the tumoral tissues and in the cell lines MIA PaCa-2 and Capan-1. HOXB7 knockdown elicited (1) an increase in the expression of the pro-apoptotic proteins BAX and BAD in both cell lines; (2) a decrease in the expression of the anti-apoptotic protein BCL-2 and in cyclin D1 and an increase in the number of apoptotic cells in the MIA PaCa-2 cell line; (3) accumulation of cell in sub-G1 phase in both cell lines; (4) the modulation of several biological processes, especially in MIA PaCa-2, such as proteasomal ubiquitindependent catabolic process and cell cycle.

Conclusion: The present study confirms the overexpression of HOXB7 mRNA expression in PDAC and demonstrates that decreasing its protein level by siRNA could significantly increase apoptosis and modulate several biological processes. HOXB7 might be a promising target for future therapies.

Keywords: Pancreatic ductal adenocarcinoma, Homeobox, HOXB7, siRNA, Gene expression

\section{Background}

PDAC is one of the most frequent causes of cancer-related death worldwide. It is an aggressive neoplasia whose early diagnosis and treatment are challenging, making it a leading cause of death by cancer [1]. Most patients are diagnosed at an advanced stage and only a few of these pa-

\footnotetext{
* Correspondence: rrgiorgi2@hotmail.com

'Laboratory for Cellular and Molecular Endocrinology (LIM-25), University of São Paulo Medical School, Av. Dr. Arnaldo, 455 \# 4305, 01246-903 São Paulo, SP, Brazil

Full list of author information is available at the end of the article
}

tients are suitable candidates for curative surgery [2,3]. Homeobox-containing genes encode DNA-binding proteins that regulate gene expression and control various aspects of morphogenesis and cell differentiation [4]. In humans, $H O X$ genes are represented by 39 members classified in four groups (HOX-A, HOX-B, HOX-C and HOX-D) located on chromosomes 7p, 17q, 12q and 2q, respectively. Aberrant expression of homeobox genes have been shown in different tumour types [5-9], including leukemias [10,11], ovarian carcinoma [12], and breast cancer [13]. The gene expression of HOXB5, HOXB6, HOXC8 and HOXD13 have

\section{Biomed Central}


already been characterized in pancreatic cancer [14]. $H O X B 7$ has an important role in various tumors. In melanomas, overexpression of $H O X B 7$ constitutively activates basic fibroblast growth factor (bFGF), favoring uncontrolled cell proliferation [15]. In a breast cancer cell line (SkBr3), transduction of $\mathrm{HOXB7}$ gene induces bFGF expression, increases growth rate and ability of cells to form colonies in semisolid medium [16]. In addition to bFGF, HOXB7 can also induce the expression of other genes, especially those related to angiogenesis and tumor invasion including vascular endothelial growth factor (VEGF), interleukin-8, angiopoietin-2, and metalloproteases 2 and 9 [17]. Increased expression of $H O X B 7$ was also described in oral squamous cell carcinoma, where it induces cell proliferation and has been shown to be associated with poor prognosis [18]. In colorectal cancer, the protein encoded by HOXB7 was considered as a prognostic factor and mediator of tumor development and progression [19]. Recently HOXB7 status was investigated in a large cohort of PDAC, the authors observed overexpression of HOXB7 and its correlation with invasive phenotype, lymph node metastasis and worse survival outcomes, but no influence on cell proliferation or viability was detected [20]. The aim of this study was to further investigate $H O X B 7$ expression in PDAC and metastatic tissues in comparison to normal pancreatic and peritumoral tissues as well as to evaluate the effects of HOXB7 knockdown in pancreatic cancer cell lines, addressing cell proliferation, apoptosis and gene expression profile.

\section{Methods}

\section{Patients and tumor characterization}

Tissue collection was carried out in compliance with The Ethical Committee of Hospital das Clínicas (Faculdade de Medicina da Universidade de São Paulo) and in accordance to The Declaration of Helsinki, with informed and free consent obtained from each subject. The following tissue samples were obtained from patients diagnosed with PDAC: tumoral $(n=29)$, disease-free tissues (located distant from the tumor site, $\mathrm{n}=24$ ) and metastatic tissues (liver metastasis, $n=6$ ). Ten normal pancreatic tissue samples obtained within 8 hours post-mortem from subjects without pancreatic diseases were used as control. The diagnosis was established by clinical, biochemical, and radiological findings and supported by the anatomopathological analysis of tumor samples.

During surgical procedure, tumor fragments were collected in sterile containers with $1 \mathrm{~mL}$ of RNAlater ${ }^{\circ}$ (Ambion, Inc., Austin, TX, USA) and stored at $4^{\circ} \mathrm{C}$. All tumoral, disease-free and metastatic samples were resected by a experienced surgeon.

\section{RNA and DNA extraction}

The material collected in RNAlater (Ambion) was fragmented in a tissue pulverizer (Mikro-Dismembrator U,
B. Braun Biotech International, Melsungen, Hesse, Germany). Total RNA was extracted from approximately $100 \mathrm{mg}$ tissue after homogenization, using with RNeasy Plus Mini Kit (Qiagen, Duesseldorf, North Rhine-Westphalia, Germany) according to manufacturer's guidelines. DNA was extracted using the DNeasy kit (Qiagen) according to the manufacturer's instructions.

Both were measured spectrophotometrically being adopted values of optical density 260/280 nm and 260/230 nm between 1.8 and 2.0. A integrity of RNA was checked by visual inspection of the $18 \mathrm{~S}$ e $28 \mathrm{~S}$ ribosomal RNA bands in $1 \%$ agarose gel, while DNA integrity was verified by the presence of a single band in agarose gel $2 \%$.

\section{Validation of endogenous reference gene}

In order to determine the most stable gene and to normalize the target gene in pancreatic tissues, we studied the expression of 32 commonly used reference genes. The expression of candidate genes was evaluated with the TaqMan Express Endogenous Control Plate, according to the manufacturer's protocol (Applied Biosystems, Foster City, CA, USA). The genes are performed in triplicate in these arrays and are constitutively expressed at moderate abundance across most test samples. cDNA was prepared from ten samples of normal pancreatic tissue and ten samples of PDAC using SuperScript ${ }^{\mathrm{TM}}$ III Reverse Transcriptase (Invitrogen Corporation, Carlsbad, CA, USA). Gene expression was measured by quantitative real time qRT-PCR and expression stability was analyzed with geNorm [21] and NormFinder [22]. Based on the results of this analysis, RPL30 was proposed as the most appropriate control gene (Figure 1).

\section{Quantitative real-time polymerase chain reaction after reverse transcription (qRT-PCR)}

Complementar DNA (cDNA) was synthesized from total RNA extracted from each cell line and tissue samples. Briefly, first-strand cDNA synthesis used $1 \mu \mathrm{g}$ of total RNA, $1 \mu \mathrm{L}$ of oligo(dT) primers $(0.5 \mu \mathrm{g} / \mu \mathrm{L}), 1 \mu \mathrm{L}$ of a solution of all four deoxyribonucleoside triphosphates (each at $10 \mathrm{mM}$ ), and $10 \times$ SuperScript $^{\mathrm{tm}}$ III Reverse Transcriptase (Invitrogen Corporation). For TaqManbased qRT-PCR, $50 \mathrm{ng}$ of cDNA was added to $10 \mu \mathrm{L}$ of $2 \times$ Taqman Universal PCR Master Mix (Applied Biosystems) and $1 \mu \mathrm{L}$ of $20 \times H O X B 7$ primers and the probe set (Applied Biosystems). The one-step RT-PCR was performed using a StepOne Plus (AB Applied Biosystems) for an initial 2 minutes incubation at $50^{\circ} \mathrm{C}$, 10 minutes incubation at $95^{\circ} \mathrm{C}$ followed by 40 cycles of PCR $95^{\circ} \mathrm{C}$ for 15 seconds and $60^{\circ} \mathrm{C}$ for 1 minute. Data values (Cycle Threshold [Ct] values) were extracted from each assay with the SDS v2.0 software tool (Applied Biosystems). 


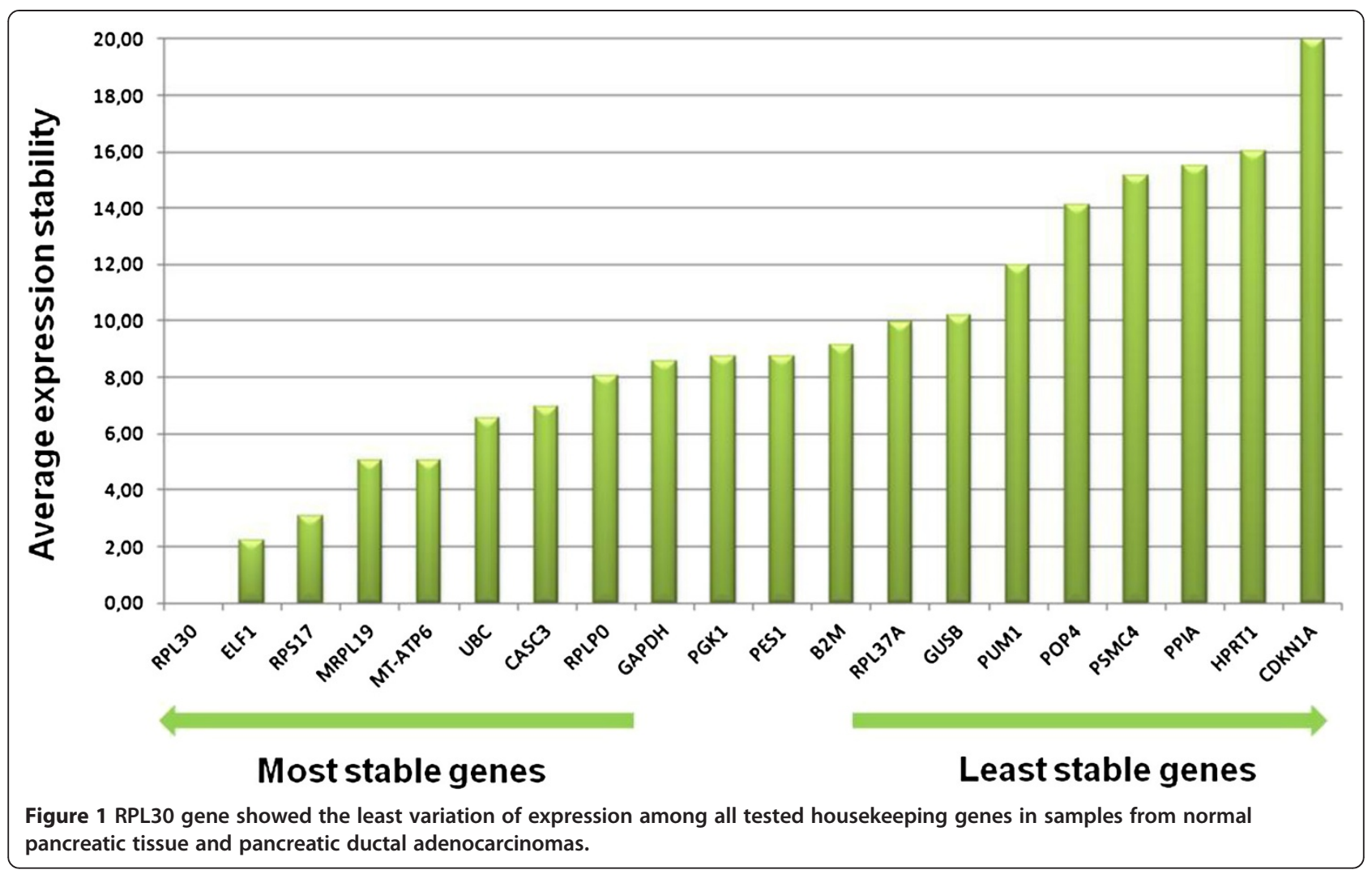

The number of specific (HOXB7) transcripts in tumor samples was normalized to housekeeping gene RPL30 mRNA in three independent experiments. Glyceraldehydes3-phosphate dehydrogenase $(G A P D H)$ was used as denominators of gene expression in cell lines. Gene expression levels were analyzed by the comparative $\mathrm{Ct}$ method $(\Delta \Delta \mathrm{Ct})$ [23].

\section{Copy number analysis of HOXB7 by real-time quantitative} PCR (qPCR)

HOXB7 amplification was assessed by qPCR using Platinum $^{\odot}$ SYBR $^{\odot}$ Green qPCR SuperMix-UDG (Invitrogen Corporation). Beta-2-microglobulin $(\beta 2 M)$ was used as reference gene for the evaluation of $H O X B 7$ copy number.

Genomic DNA (100 ng/ $\mu \mathrm{L}$ ) from each tissue sample was conducted on a Applied Biosystems StepOne Plus (Applied Biosystems, Foster City, CA, USA) using the following primers for genomic sequences of $H O X B 7$ (sense: 5 ' - CGA TGC AGG GCT TGT ACC -3'; anti-sense: 5' - AGG CGC CTT CAG GGT AAT -3') and $\beta 2 M$ (sense: $5^{\prime}$ - CGT GTG AAC CAT GTG ACT TTG -3'; anti-sense: 5' - GAA TTC ATC CAA TCC AAA TGC -3'). The reaction was incubated for 5 minutes at $94^{\circ} \mathrm{C}$, followed by 40 cycles of 30 seconds at $94^{\circ} \mathrm{C}, 30$ seconds at $55^{\circ} \mathrm{C}$, and 90 seconds at $72^{\circ} \mathrm{C}$, with a final extension of $72^{\circ} \mathrm{C}$ for 7 minutes. All samples were run in duplicate and positive $H O X B 7$ gene amplification was defined as a copy number of $>3$ [24].

\section{Cell culture}

Human pancreatic cancer cell line MIA PaCa-2 was obtained from American Type Culture Collection (ATCC ${ }^{\oplus}$ Number: CRL-1420 ${ }^{\mathrm{Tm}}$, Manassas, VA, USA). The cells were maintained routinely in Roswell Park Memorial Institute (RPMI) 1640 medium (Invitrogen Corporation, Carlsbad, CA, USA) supplemented with $10 \%$ fetal bovine serum (FBS, Invitrogen Corporation), $100 \mathrm{U} / \mathrm{mL}$ penicillin $\mathrm{G}$ (Invitrogen Corporation), and $0.1 \mathrm{mg} / \mathrm{mL}$ streptomycin sulfate (Invitrogen Corporation) at $37^{\circ} \mathrm{C}$ in a humidified, $5 \%$ $\mathrm{CO}_{2}, 95 \%$ air atmosphere. Capan-1 cell line established from a hepatic metastasis of a PDAC was also obtained from ATCC (Number: HTB-79 ${ }^{\mathrm{rm}}$ ). The cells were grown in IMDM medium (Invitrogen Corporation) supplemented with 20\% FBS (Invitrogen Corporation).

\section{RNAi knockdown (siRNA) and transfection}

The human pancreatic cancer cell lines were cultured as described. siRNA and transfections were performed following the manufacturer's protocols of the TriFECTa Dicer- Substrate RNAi kit (IDT, Coralville, IA, USA) and Lipofectamine RNAi Max Reagent (Invitrogen Corporation). $10^{5}$ cells were plated in 6-well in RPMI medium one day prior to transfection. Cells were transfected with 


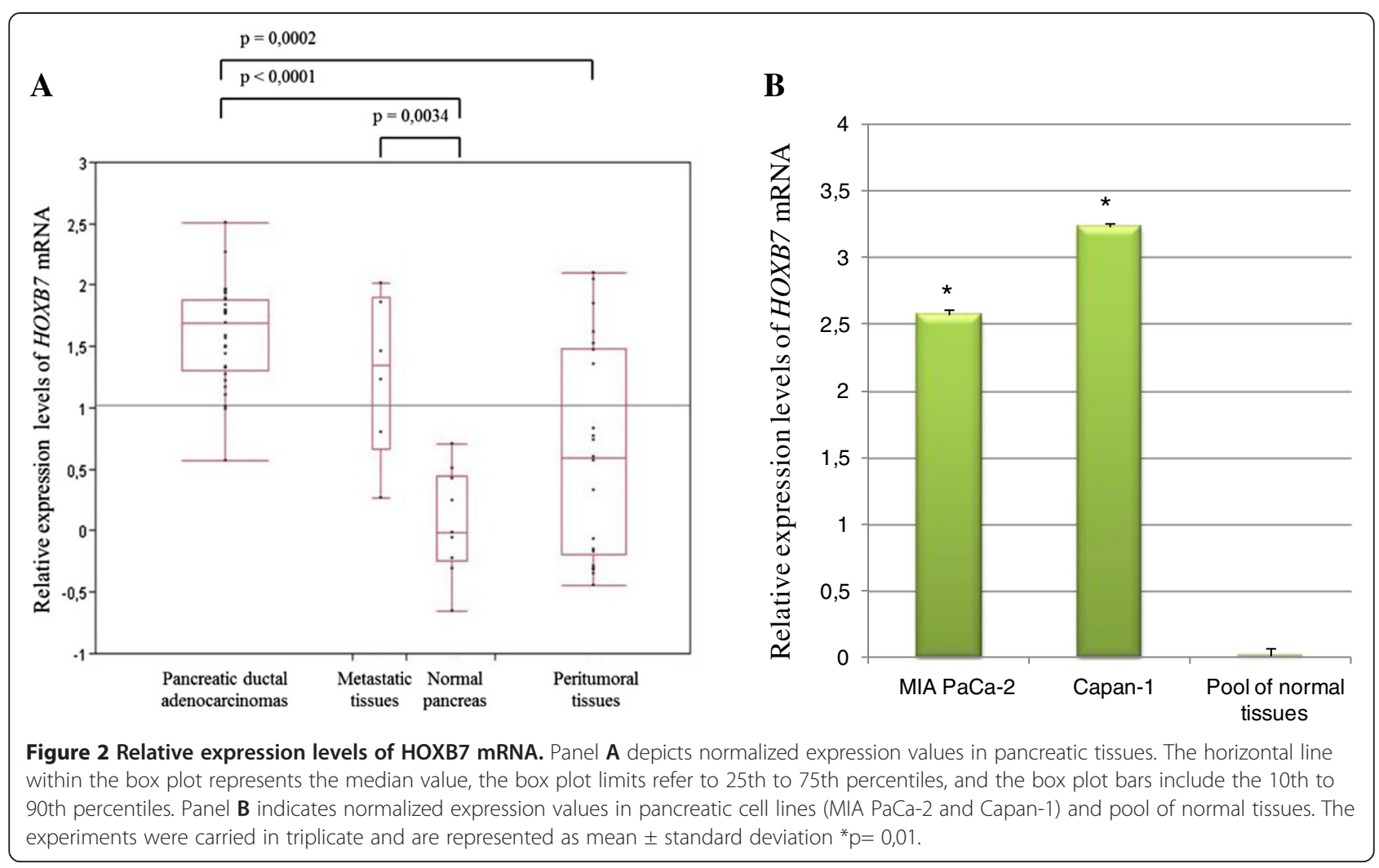

a nonspecific scrambled siRNA and with a HOXB7-specific siRNA at a final concentration of $10 \mathrm{nM}$. The mRNA content was measured 48 hours after transfection. All transfections were minimally performed in duplicate. HOXB7 depletion and RT-qPCR were performed as described above. Each experiment was repeated at least twice.

\section{Western blotting}

After 48 h electroporation with siRNAs, cells were homogenized in RIPA buffer (Cell Signaling Technology, Danvers, MA, USA) with protease inhibitors (Complete, Mini, EDTA-free Protease Inhibitor Cocktail Tablet, Roche Applied Science, Penzberg, Upper Bavaria, Germany). The homogenate was centrifuged at 16,700 $\mathrm{g}$ for 30 minutes at $4^{\circ} \mathrm{C}$. Protein concentration was measured using Lowry method [25].

Thirty micrograms of total protein was separated on a $14 \%$ sodium dodecyl sulfate polyacrylamide gel followed by transfering to an Immobilon-P membrane (Merck Millipore, Billerica, MA, USA). Membranes were incubated for 18 hours in $5 \%$ skim milk phosphate buffer saline (PBS) with mouse monoclonal antibody HOXB7 (1:50, ab51237, Abcam Inc, Cambridge, MA, USA) followed by incubation with secondary antibody (1:400, RPN1001, GE Healthcare, Little Chalfont, Buckinghamshire, UK) and labeled with horseradish peroxidase (1:3000, GE Healthcare). Rabbit anti-beta actin antibody
(1:1000, ab8227, Abcam Inc, Cambridge, MA, USA) was used as internal control. Photographic film was exposed to the membrane in a dark room.

\section{MTT cell proliferation assay}

Cell proliferation was evaluated after 24 hours, 48 hours and 72 hours after transfection with siRNA-HOXB7 using a specific colorimetric assay. In particular, cells were exposed to $H O X B 7$ siRNA and then stained with 3-(4,5dimethylthiazol-2-yl) - 2,5-diphenyltetrazolium bromide (MTT, Sigma-Aldrich, St Louis, MO, USA). The absorbance was measured by ELx 808 Ultra Microplate Reader (Bio-Tek Instruments, Inc, Winooski, VT, USA) at a wavelength of $570 \mathrm{~nm}$.

\section{Flow cytometry - markers, cell cycle distribution, and apoptosis analysis}

Forty-eight hours after transfection, the human pancreatic cells lines were trypsinized and inactivated with FBS, centrifuged at $1,500 \mathrm{rpm}$ for $10 \mathrm{~min}$, and the supernatant was discarded. The pellet was resuspended in 5 $\mathrm{mL}$ of PBS at a concentration of $10^{6}$ cells $/ \mathrm{mL}$. To analyze intracytoplasmic and nuclear markers, cells were permeabilized with $5 \mu \mathrm{L}$ of $0.1 \%$ Triton X-100 for 30 min before the addition of specific primary antibodies. The following markers were used to determine cell death pathways: Bax (Ab5714, Abcam Inc), Bad Ab32445, Abcam Inc), and Bcl-2 (Ab692, Abcam Inc). 


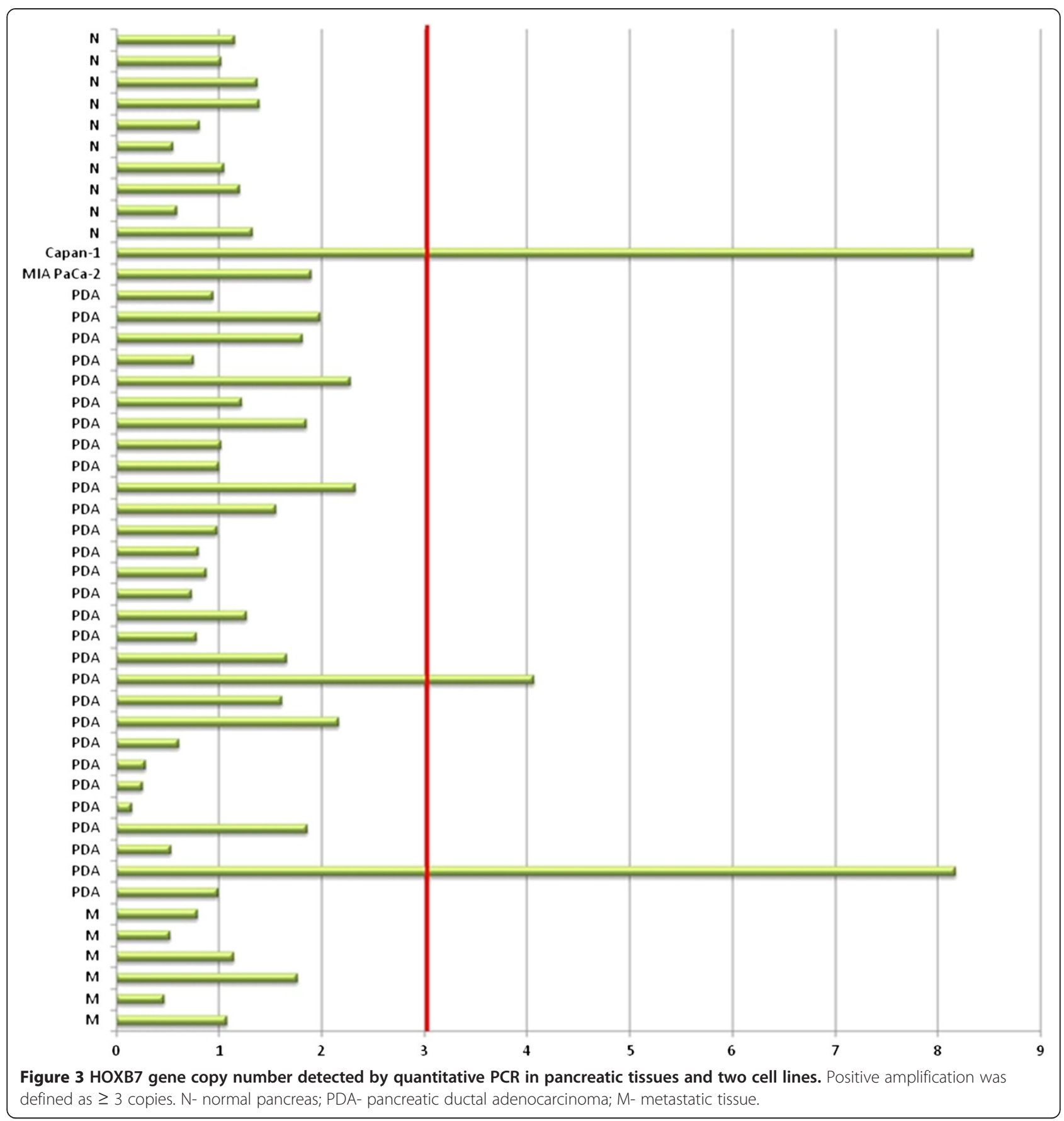

Antibodies for cyclin D1 (sc8396, Santa Cruz Biotechnology Inc, Santa Cruz, CA, USA) were used to determine the proliferation index. The samples were analyzed in a flow cytometer (FACSCalibur, BD, Franklin Lakes, NJ, USA), and expression of cell proliferation and cell death markers were compared with parental control cells.

Detection of the markers was followed by analysis of the cell cycle phases. In this step, the trypsinized cells were treated with $70 \%$ ice-cold ethanol containing 100 $\mu \mathrm{g} / \mathrm{mL}$ RNase. They were then washed and incubated in $\mathrm{PBS}$ at $37^{\circ} \mathrm{C}$ for 45 minutes. The labeling was performed in a solution containing propidium iodide (PI) at a concentration of $1.8 \mathrm{mg} / \mathrm{mL}$ to assess the integrity and quantity of DNA in the cell cycle phases.

Evaluation of apoptosis was carried out using Annexin V FITC Apoptosis Detection kit I (BD) according to the manufacturer's instructions. Cells were centrifuged and the cell pellet was suspended with binding buffer $(100 \mu \mathrm{L})$ and then incubated with Annexin V-FITC $(2 \mu \mathrm{L})$ 


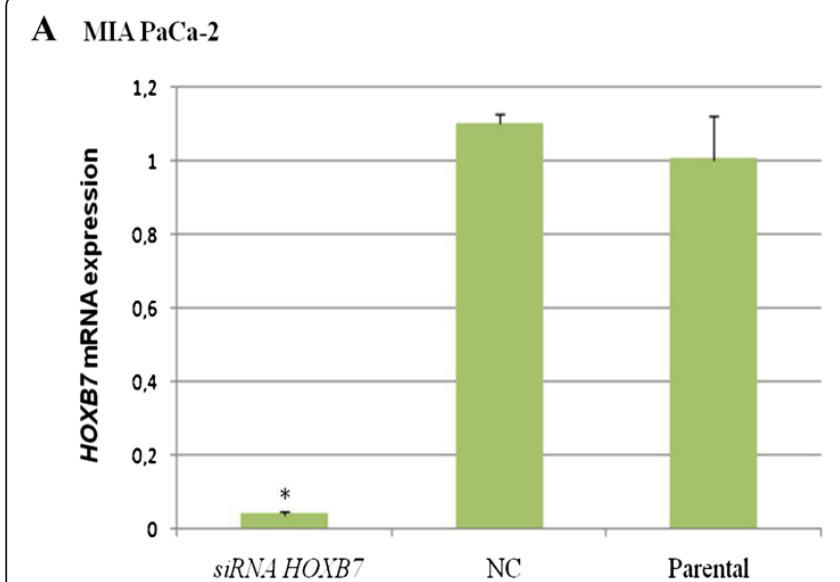

B MIA PaCa-2

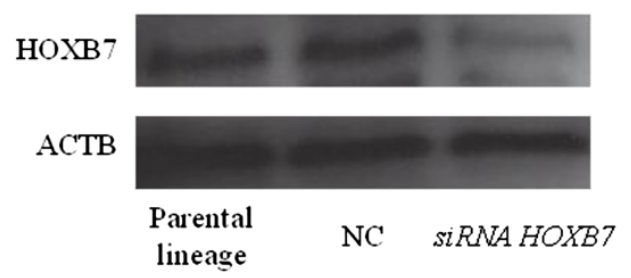

Capan-1

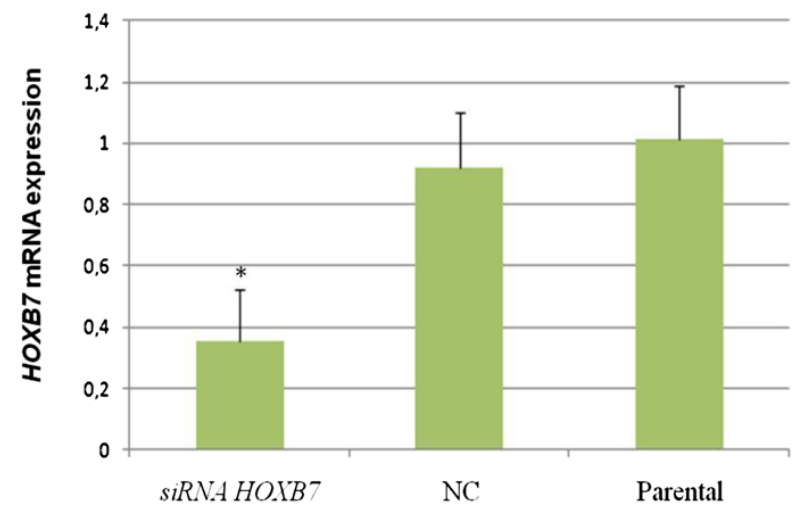

Capan-1

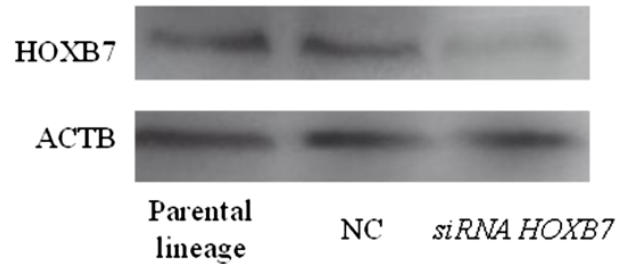

Figure 4 HOXB7 gene expression 48 hours after transfection of siRNA. Panel A depicts relative expression levels of HOXB7 mRNA in MIA $\mathrm{PaCa}-2\left({ }^{*} \mathrm{p}=0.0270\right)$ and Capan- $1\left({ }^{*} \mathrm{p}=0.0003\right)$ cells lines; the experiments were carried in triplicate and are represented as mean \pm standard deviation. Panel $\mathbf{B}$ depicts HOXB7 protein expression; beta-actin was used as internal control. NC- negative control.

and PI $(2 \mu \mathrm{L})$ for 15 minutes, at room temperature in the dark. After incubation, $400 \mu \mathrm{L}$ of binding buffer was added and cells were analyzed in a FACScalibur (BD) using CellQuest software for determining the percentage of apoptotic cells. A minimum of 10,000 events was acquired for each sample [26].

\section{Microarray analysis after knockdown of HOXB7}

Total RNA derived from the inhibition of gene transcript HOXB7 as well as from parental cells were quantified in Bioanalyzer (Agilent, Santa Clara, CA, USA). This procedure was performed in duplicate for all cell lines, which were sorted into treated and untreated with

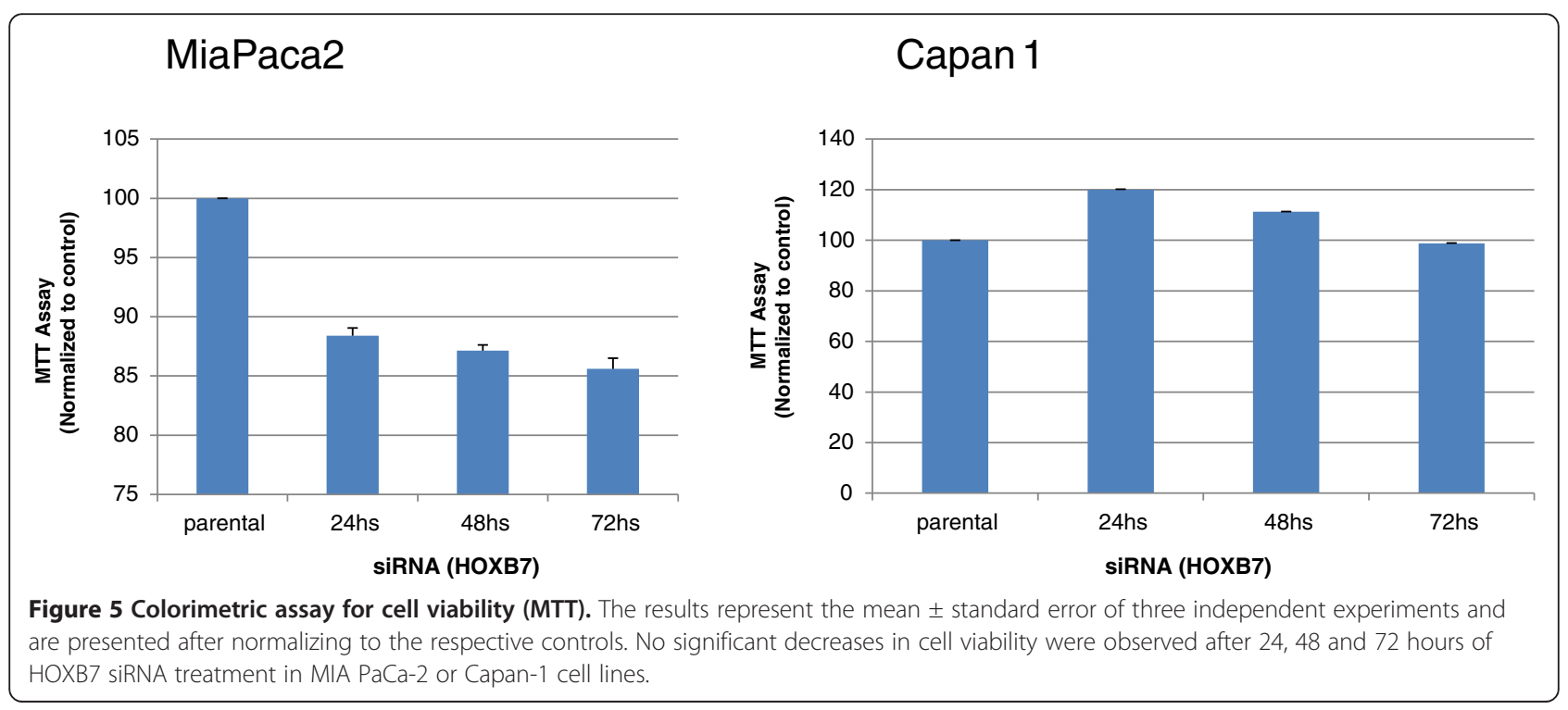




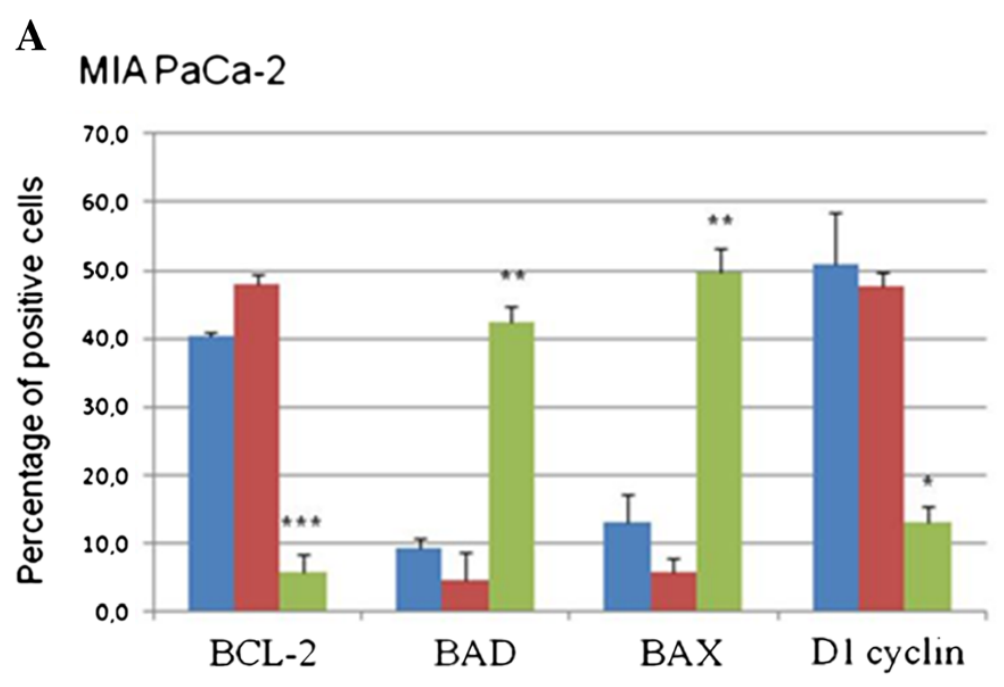

\section{B Capan-1}

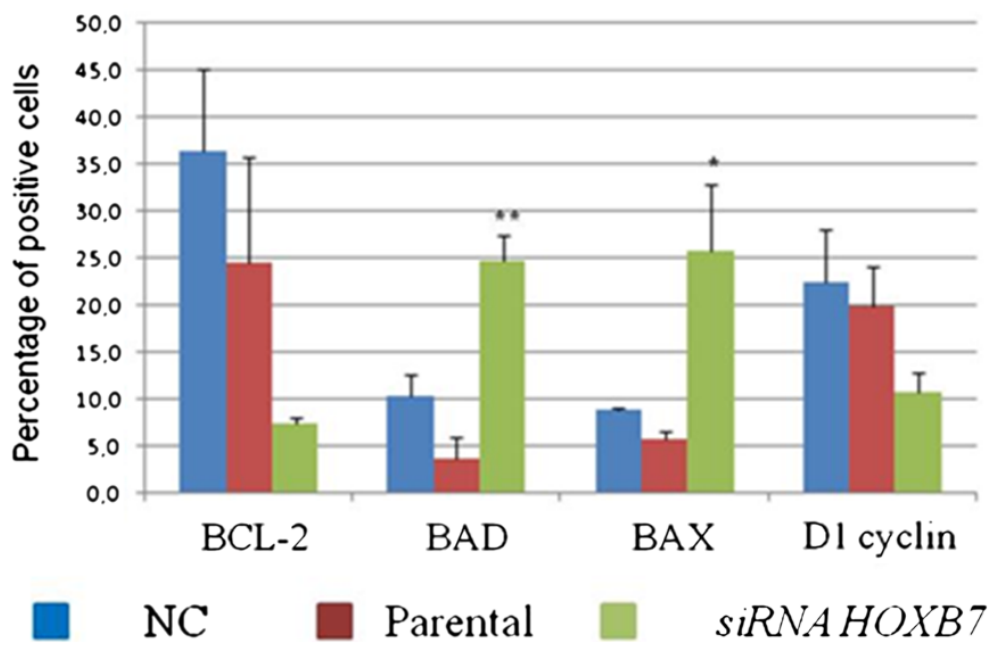

Figure 6 BCL-2, BAD, BAX and D1 cyclin expression as evaluated by flow cytometry. Panels A and B demonstrate MIA PaCa-2 and Capan-1 cells lines, respectively. The experiments were carried out in triplicate and the bars represent mean \pm standard deviation. NC- negative control. ${ }^{*} p<0.05,{ }^{* *} p<0.01,{ }^{* * *} p<0.001$.

siRNA. Each reaction was prepared from $200 \mathrm{ng}$ of total RNA in a volume of $1,5 \mu \mathrm{L}$. The guidelines of the protocol One-Color Microarray-Based Gene Expression (Agilent, Santa Clara, CA, USA) were followed with the use of Agilent Low Input Quick Amp Labeling Kit. Hybridized slides (Human 4x44K Microarray) were washed as recommended and scanned using the HighResolution Microarry Scanner (Agilent, Santa Clara, CA, USA). Data were extracted with Agilent Technologies Feature Extraction Software version 9.5.3.

\section{Validation of microarray assay}

Validation of microarray was performed from the analysis of E2F and RB1 mRNA expression in Mia PaCa-2 cell line by RT-qPCR. The experiment was performed as described previously.

\section{Statistical analysis}

For analysis of HOXB7 expression and amplification statistical tests were two-tailed, with statistical significance fixed at 0.05 . Continuous variables were analyzed using KruskalWallis and Mann-Whitney U nonparametric tests. Values were expressed as median, minimum and maximum values. Data were analyzed using JMP Software version 8 (SAS Institute Inc, Cary, NC, USA).

Statistical analysis of MTT and flow cytometry was performed by analysis of variance (ANOVA) with the multiple comparison test of Tukey-Kramer. Values were 


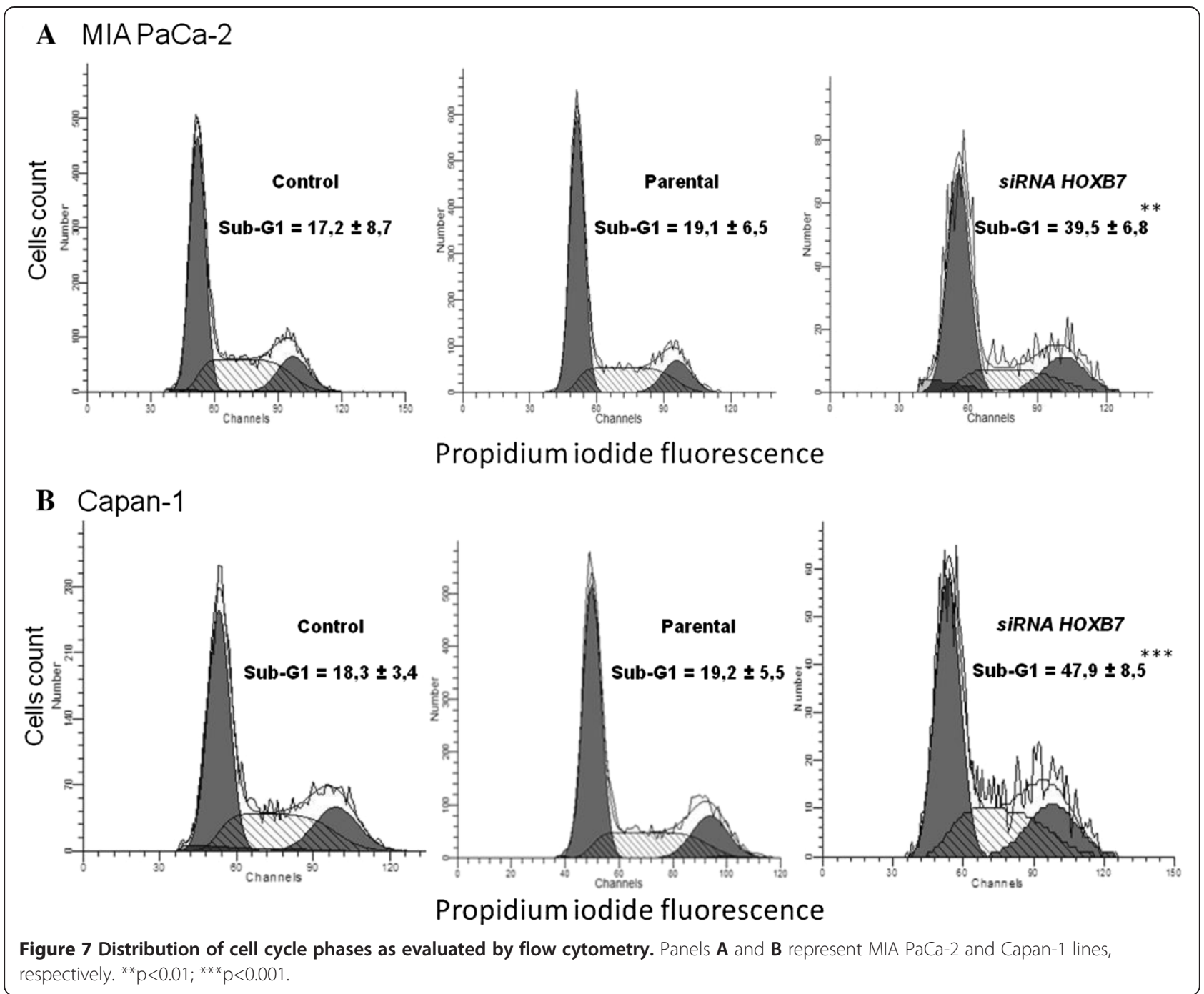

expressed as mean \pm standard deviation, considering as significant $\mathrm{p}$ values $<0.05$.

Analysis of data obtained from the microarray experiment was performed using the self-HT [27]. The self-self experiments were performed with duplicates untreated labeled with Cy3 (untreated lineage $\mathrm{x}$ untreated lineage), assuming, then, that the variability of signal in microarray experiments is dependent of the intensity and any difference in hybridization is product of experimental artifact. From the self-self, a credibility interval of $99 \%$ was established to differentiate changes in expression of technique artifact, resulting therefore in determining intensitydependent cutoffs, which were used in the experiments non-self-self (treated lineage $x$ untreated lineage). On the platform array, the same gene is shown more than once by different probes, therefore, three criteria have been defined for identifying genes differentially expressed: (1) each gene was represented by at least two probes; (2) more than $50 \%$ of the probes representing one particular gene presented signal after expression quality analysis; (3) there was 100\% agreement between the probe signal (up regulation or down regulation). Microarray data are available through the Minimum Information About a Microarray Experiment (MIAME, accession number GSE46393).

Two lists of differentially expressed genes were generated for each cell line, one containing the upregulated genes and other presenting downregulated genes common to the experimental duplicates. Each list was annotated in categories of biological processes according to the Gene Ontology database and the analysis was performed in WebGestalt [28]. The results were seen in directed acyclic graphs to maintain the relationship between categories enriched.

Hypergeometric test was used to evaluate the categorical enrichment and as multiple categories were tested simultaneously, $p$ values were adjusted according to the adjustment method of multiple test proposed by 


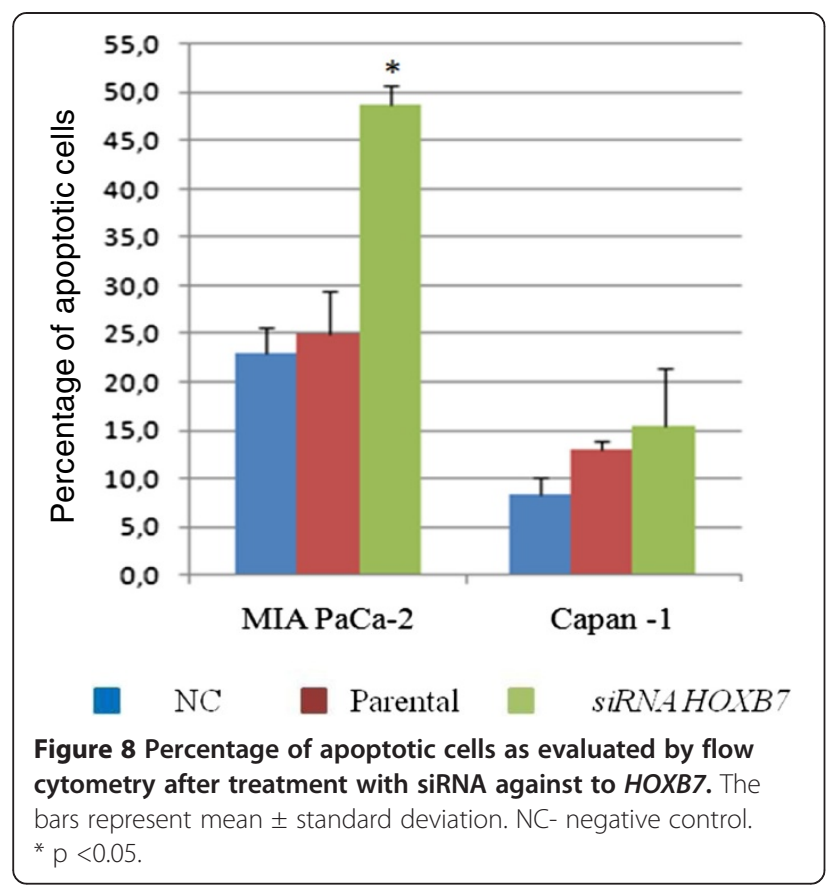

Benjamini and Hochberg [29]. The significance for enrichment analysis was fixed at 0.01 . Furthermore, a minimum number of two genes were established as the cutoff required.

\section{Results}

\section{HOXB7 mRNA expression in pancreatic tissue samples and cell lines}

HOXB7 mRNA expression was analyzed in 29 pancreatic ductal adenocarcinoma samples, 24 peritumoral tissue samples, 6 metastatic tissues samples, and 10 normal pancreatic tissue samples. A higher content of HOXB7 mRNA was observed in tumoral and in metastatic tissues in comparison to normal pancreas (control) (Figure 2A). HOXB7 mRNA overexpression was also observed in MIA $\mathrm{PaCa}-2$ and Capan-1 cell lines (Figure 2B).

The number of copies of HOXB7 was determined in all tissue samples and in both cell lines with the purpose of investigate the possibility of genomic amplification. As shown in Figure 3, only two tumoral samples and the Capan-1 cell line presented more than three copies of HOXB7 gene.

\section{HOXB7 silencing evaluation}

The two human pancreatic cell lines MIA PaCa-2 and Capan-1 were transiently transfected with two siRNA duplexes targeting different encoding regions of human HOXB7 mRNA, named as siRNA1 and siRNA2 or a nonspecific scrambled siRNA control. After 48 hours, the HOXB7 mRNA and protein levels were quantified by real time RT-PCR and western blot, respectively. HOXB7
Table 1 Biological processes associated with HOXB7 transcript inhibition in MIA PaCa-2 cell lineage

\begin{tabular}{|c|c|}
\hline \multicolumn{2}{|c|}{ Biological process } \\
\hline $\begin{array}{l}\text { Cellular macromolecular complex } \\
\text { assembly }\end{array}$ & $\begin{array}{l}\mathrm{C}=336 ; \mathrm{O}=32 ; \mathrm{E}=13.19 ; \mathrm{R}=2.43 ; \\
\operatorname{rawP}=3.34 \mathrm{e}-06 ; \mathrm{adj} P=0.0012\end{array}$ \\
\hline $\begin{array}{l}\text { Macromolecular complex subunit } \\
\text { organization }\end{array}$ & $\begin{array}{l}\mathrm{C}=741 ; \mathrm{O}=55 ; \mathrm{E}=29.09 ; \mathrm{R}=1.89 ; \\
\operatorname{rawP}=3.63 \mathrm{e}-06 ; \mathrm{adj} \mathrm{P}=0.0012\end{array}$ \\
\hline Macromolecular complex assembly & $\begin{array}{c}\mathrm{C}=672 ; \mathrm{O}=51 ; \mathrm{E}=26.38 ; \mathrm{R}=1.93 ; \\
\operatorname{rawP}=4.49 \mathrm{e}-06 ; \mathrm{adj} \mathrm{P}=0.0012\end{array}$ \\
\hline Organelle organization & $\begin{array}{l}C=1339 ; O=87 ; E=52.57 ; R=1.66 ; \\
\quad r a w P=1.38 e-06 ; a d j P=0.0012\end{array}$ \\
\hline $\begin{array}{l}\text { Cellular macromolecular complex } \\
\text { subunit organization }\end{array}$ & $\begin{array}{l}\mathrm{C}=396 ; \mathrm{O}=36 ; \mathrm{E}=15.55 ; \mathrm{R}=2.32 ; \\
\operatorname{rawP}=2.42 \mathrm{e}-06 ; \mathrm{adj} \mathrm{P}=0.0012\end{array}$ \\
\hline Protein complex assembly & $\begin{array}{l}C=520 ; O=42 ; E=20.41 ; R=2.06 ; \\
\operatorname{rawP}=7.28 \mathrm{e}-06 ; \mathrm{adj} P=0.0014\end{array}$ \\
\hline Protein complex biogenesis & $\begin{array}{l}C=520 ; O=42 ; E=20.41 ; R=2.06 ; \\
\operatorname{rawP}=7.28 \mathrm{e}-06 ; \mathrm{adj} P=0.0014\end{array}$ \\
\hline Cellular protein complex assembly & $\begin{array}{l}C=184 ; O=21 ; E=7.22 ; R=2.91 ; \\
\text { rawP }=1.12 e-05 ; \operatorname{adj} P=0.0019\end{array}$ \\
\hline $\begin{array}{l}\text { Proteasomal ubiquitin-dependent } \\
\text { protein catabolic process }\end{array}$ & $\begin{array}{l}\mathrm{C}=107 ; \mathrm{O}=15 ; \mathrm{E}=4.20 ; \mathrm{R}=3.57 ; \\
\operatorname{raw} \mathrm{P}=1.79 \mathrm{e}-05 ; \mathrm{adj} \mathrm{P}=0.0022\end{array}$ \\
\hline $\begin{array}{l}\text { Proteasomal protein catabolic } \\
\text { process }\end{array}$ & $\begin{array}{l}C=107 ; O=15 ; E=4.20 ; R=3.57 ; \\
\text { raw } P=1.79 e-05 ; a d j P=0.0022\end{array}$ \\
\hline $\begin{array}{l}\text { Interspecies interaction between } \\
\text { organisms }\end{array}$ & $\begin{array}{l}\mathrm{C}=280 ; \mathrm{O}=27 ; \mathrm{E}=10.99 ; \mathrm{R}=2.46 ; \\
\text { rawP }=1.56 \mathrm{e}-05 ; \mathrm{adj} P=0.0022\end{array}$ \\
\hline Cell cycle & $\begin{array}{l}\mathrm{C}=895 ; \mathrm{O}=60 ; \mathrm{E}=35.14 ; \mathrm{R}=1.71 ; \\
\operatorname{rawP}=2.98 \mathrm{e}-05 ; \mathrm{adj} P=0.0033\end{array}$ \\
\hline Amine biosynthetic process & $\begin{array}{l}\mathrm{C}=78 ; \mathrm{O}=12 ; \mathrm{E}=3.06 ; \mathrm{R}=3.92 ; \\
\operatorname{raw} \mathrm{P}=4.83 \mathrm{e}-05 ; \mathrm{adj} \mathrm{P}=0.0050\end{array}$ \\
\hline $\begin{array}{l}\text { Positive regulation of ubiquitin- } \\
\text { protein ligase activity }\end{array}$ & $\begin{array}{r}C=67 ; O=11 ; E=2.63 ; R=4.18 \\
\operatorname{raw} P=5.37 e-05 ; \operatorname{adj} P=0.0052\end{array}$ \\
\hline Positive regulation of ligase activity & $\begin{array}{r}\mathrm{C}=70 ; \mathrm{O}=11 ; \mathrm{E}=2.75 ; \mathrm{R}=4.00 ; \\
\operatorname{rawP}=8.13 \mathrm{e}-05 ; \mathrm{adj} \mathrm{P}=0.0073\end{array}$ \\
\hline Chromatin organization & $\begin{aligned} & C=364 ; O=30 ; E=14.29 ; R=2.10 ; \\
& \operatorname{rawP} P=0.0001 ; \operatorname{adj} P=0.0084\end{aligned}$ \\
\hline
\end{tabular}

$\mathrm{C}$ - Reference genes in the category, O- number of genes in the gene set and also in the category, E- expected number in the category, R- ratio of enrichment, rawP- $p$ value from hypergeometric test, adjP- $p$ value adjusted by the multiple test adjustment.

siRNA significantly silenced the content of $H O X B 7$ mRNA in both pancreatic cell lines while the scrambled siRNA had no effect (Figure 4A). Approximately 96\% and $65 \%$ of $H O X B 7$ mRNA were silenced in MIA PaCa2 and Capan-1 cells, respectively. Western Blotting analysis also demonstrated that HOXB7 siRNAs decreased proteins level in both cell lines (Figure 4B).

\section{MTT assay}

The impact of siRNA transfection on cell viability was investigated after 24, 48, and 72 hours of incubation, using the MTT assay. As shown in Figure 5, no significant differences in absorbance were observed in comparison to the parental cells. 


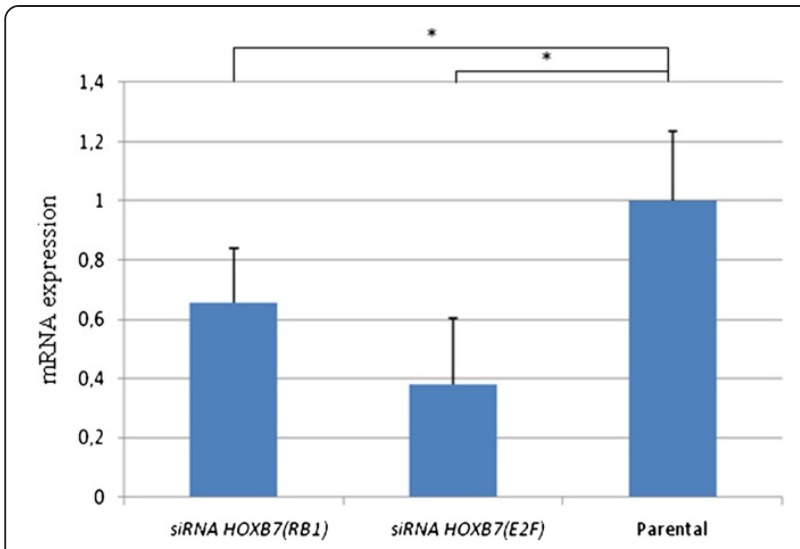

Figure 9 Validation of microarray assay by qRT-PCR. RB1 and E2F gene relative expression 48 hours after transfection of HOXB7specific siRNA. The experiments were carried in triplicate and are represented as mean \pm standard deviation ${ }^{*} \mathrm{p}<0,05$.

\section{Flow cytometric analyses of markers of proliferation and} cell death

Modulation of BAX, BAD (pro-apoptotic), BCL-2 (antiapoptotic) and D1 cyclin (marker of cell proliferation) were evaluated after 48 hours of treatment with HOXB7 siRNA. An increased in the expression of the pro-apoptotic proteins BAX and BAD was observed in both cell lines $(\mathrm{p}<0.01)$, while expression of BCL-2 and cyclin D1 were significantly decreased by treatment in MIA PaCa-2 cell line $(\mathrm{p}<0.01$ and $\mathrm{p}<0.05$ respectively) (Figure 6A). In the Capan-1 cell line, there was an increase in the expression of the pro-apoptotic BAX and BAD proteins $(\mathrm{p}<0.01$ and $\mathrm{p}<0.05$, respectively), but BCL-2 and D1 cyclin expression remained unchanged after treatment (Figure 6B).

Cell cycle distribution was assessed after staining fixed cells with PI and thereby cells in different phases of cell cycle were discriminated: G1, S, G2/M; siRNAtransfected cell lines vs. scrambled control and parental demonstrated an accumulation of cells in sub-G1 phase in MIA PaCa-2 (Figure 7A) and Capan-1 (Figure 7B).

The process of apoptosis was assessed 48 hours after inhibition of $H O X B 7$ mRNA in the two cell lines studied; only MIA PaCa- 2 cell line demonstrated an increase in the percentage of apoptotic cells after treatment (Figure 8).

\section{Effects of HOXB7 silencing in gene expression profile of PDAC cell lines}

In MIA PaCa-2, 679 genes were identified as downregulated after $H O X B 7$ silencing in comparison to parental cells. The genes were grouped into different categories according to the biological process (Table 1). On the order hand, 12 genes were downregulated and 96 were upregulated in treated Capan-1 cell line compared to parental cells, which were not grouped due to the established statistical cut.

\section{Downregulation of E2F and RB1 genes in MIA PaCa-2 after HOXB7 silencing}

Among the downregulated genes in MIA PaCa-2 after inhibition of $H O X B 7$, we validated the RB1 and E2F transcript expression. As shown in Figure 9, the two downregulated genes were confirmed by quantitative real time PCR.

\section{Discussion}

The main findings of the present study was confirmation of $H O X B 7$ mRNA overexpression in PDAC as well as the demonstration that its knockdown in two human PDAC cell lines increases expression of the proapoptotic proteins BAX and BAD, elicits an accumulation of cells in the sub-G1 phase and modulates cellular gene expression profile.

Nguyen et al. [20] have previously demonstrated overexpression of $\mathrm{HOXB7}$ mRNA in PDAC, which was positively correlated with lymph node metastasis and considered a predictor of poor prognosis. In that study, knockdown of $H O X B 7$ by siRNA in the pancreatic cell lines BxPC3, MIA PaCa-2 and PANC1 resulted in decreased invasion but it did not influence cell proliferation or viability as evaluated by the MTT assay [20]. This latter result was also observed in the present study, concomitantly with increased apoptosis as evaluated by flow cytometry in MIA Paca-2 cell line. These apparent discrepant results between the MTT assay and flow cytometry may reflect limitations of the MTT assay, since the metabolic activity measured by this methodology may be changed by different conditions or chemical treatments [30].

Knockdown of $\mathrm{HOXB7}$ mRNA promoted an increase in the expression of the pro-apoptotic BAD and BAX proteins in both studied cell lines, but the pattern of expression of the anti-apoptotic BCL2 protein differed between them: in MIA PaCa-2, there was a reduction in BCL2 expression, while no significant changes were detected in the Capan-1 cell line. Additionally, downregulation of cyclin D1 also took place only in MIA PaCa- 2 cells. The sum of these events may explain the increased apoptosis induced by $H O X B 7$ siRNA only in MIA Paca-2 cell line.

MIA PaCa-2 and Capan-1 cell lines are derived from pancreatic cancer and we have evaluated both because the first was established from a primary tumor [31] while Capan-1 derived from a hepatic metastasis [32]. They are known to present distinct phenotypic and genotypic characteristics, such as adhesion, invasion, migration, and expression status of commonly altered genes (KRAS, p53, p16, and SMAD4) [33]. Thus, it is 
not surprising that these cell lines may exhibit distinct behaviors, as already described in other experimental conditions [33].

According to Hyman et al. gene amplification may be an important mechanism underlying the increased expression of HOXB7 in breast cancer. However, gene amplification was detected in only $10 \%$ of the tested samples [34]. The analysis of $H O X B 7$ gene copy number in the present study suggests that its increased expression in PDAC does not result from gene amplification, which was identified in only two tumoral samples and in the Capan1 cell line. It is possible that overexpression of $H O X B 7$ is linked to epigenetic events, which have already been described for other $H O X$ family members [35].

Regardless of the mechanism by which $H O X B 7$ mRNA expression is upregulated in PDAC, we have demonstrated that its knockdown increases apoptosis and also modulates several biological processes only in MIA $\mathrm{PaCa}-2$. Some of the identified biological processes were already described as affected by HOX genes in other cell types. For instance we have observed downregulation of genes belonging to proteasomal ubiquitin-dependent catabolic protein process whereas Wang et al. [36] reported that upregulation of HOXA10 in myeloid cells enhances the protein-dependent ubiquitination of the ubiquitin ligase Triad-1.

We have also shown that suppression of HOXB7 mainly caused an imbalance in the cell cycle, especially in MIA $\mathrm{PaCa}-2$ cell line, which presented not only downregulation of genes associated with cell cycle in the microarray, but also a reduction of expression of Cyclin D1 in the flow cytometry analysis. This event was also reported by Liao et al. [19], who detected downregulation of cyclin D1 and upregulation of p27 after $H O X B 7$ gene silencing with consequent blocking G1-S. Here, we showed $E 2 F$ and retinoblastoma B1 (RB1) wich are essential for the G1-S transition. These downregulated transcripts were identified by microarray and confirmed by quantitative real time PCR.

Understanding the molecular abnormalities involved in the pathogenesis of PDAC may reveal new targets for therapy and inhibition of mRNA expression mediated by siRNA can be used to unravel the role of specific genes in the tumorigenic process. In this sense, in the present study, the inhibition of HOXB7 expression in MIA $\mathrm{PaCa}-2$ and Capan-1 cell lines corroborated the participation of this homeobox gene in the development of PDAC, reinforcing the need for further investigation.

Although the chemotherapeutic agent gemcitabine represents the standard for pancreatic cancer treatment, its use is far from ideal, as prolonged exposure leads to drug resistance. This is a major cause of treatment failure for pancreatic adenocarcinoma and novel therapeutic approaches are needed $[37,38]$. The use of RNA interference as a therapeutic modality has generated great expectations, however, finding a way to efficiently deliver it to cancer cells is challenging. The inhibition of HOXB7 by RNA interference in PDAC could be a promising target to be used in combination with conventional chemotherapy.

\section{Conclusions}

HOXB7 is overexpressed in pancreatic adenocarcinomas and in the two studied pancreatic cell lines; the siRNA assay suggests that $H O X B 7$ is involved in pancreatic cell proliferation and apoptosis. HOXB7 is another component of the extensive network of molecules involved in the pathobiology of pancreatic cancer and might constitute a promising target for future biological therapies.

\section{Competing interests}

The authors declare that they have no competing interests.

\section{Authors' contributions}

RRG designed the study and wrote the manuscript, TC performed most of the experiments with help from MAHZF, RDP and VdJRdP contributed to western blot and bioinformatics analyses, DMA contributed in flow cytometry analyses, MSK provided the tumoral samples, TB performed surgical procedures, MLCG, HMB and EMN critically revised the manuscript and made many conceptual suggestions. All authors read and approved the final manuscript.

\section{Acknowledgments}

This study was supported in part by a FAPESP grant 2010/01421-1.

\section{Author details}

${ }^{1}$ Laboratory for Cellular and Molecular Endocrinology (LIM-25), University of São Paulo Medical School, Av. Dr. Arnaldo, 455 \# 4305, 01246-903 São Paulo, SP, Brazil. 'Department of Gastroenterology (LIM-07 and 37), University of São Paulo School of Medicine, Sao Paulo, SP, Brazil. ${ }^{3}$ Institute of Psychiatry University of Sao Paulo, Medical School (FMUSP), São Paulo, SP, Brazil. ${ }^{4}$ Laboratory of Biochemistry and Biophysics, Butantan Institute, Av. Vital Brazil, 1500, 05503-900 São Paulo, Brazil. ${ }^{5}$ CIPE - AC Camargo Hospital, São Paulo, SP, Brazil. ${ }^{6}$ Institute of Psychiatry - University of Sao Paulo, Medical School (FMUSP), São Paulo, SP, Brazil. 'Laboratory Molecular Biology- Fundação Pró-Sangue Hemocentro of São Paulo, São Paulo, SP, Brazil. ${ }^{8}$ Pediatric Clinical Laboratory (LIM 36), University of São Paulo, Medical School (FMUSP), São Paulo, SP, Brazil.

Received: 19 February 2013 Accepted: 26 September 2013 Published: 2 October 2013

\section{References}

1. Jemal A, Siegel R, Xu J, Ward E: Cancer statistics. CA Cancer J. Clin 2010, 60:277-300.

2. Herreros-Villanueva M, Hijona E, Cosme A, Bujanda L: Adjuvant and neoadjuvant treatment in pancreatic cancer. World J Gastroenterol 2012, 18(14):1565-72.

3. Páez D, Labonte MJ, Lenz HJ: Pancreatic cancer: medical management (novel chemotherapeutics). Gastroenterol Clin North Am 2012, 41(1):189-209.

4. Mark M, Rijli FM, Chambon P: Homeobox genes in embryogenesis and pathogenesis. Pediatr Res 1997, 42(4):421-9.

5. Grier DG, Thompson A, Kwasniewska A, McGonigle GJ, Halliday HL, Lappin TR: The pathophysiology of HOX genes and their role in cancer. J Pathol 2005, 205(2):154-71.

6. Nunes FD, de Almeida FC, Tucci R, de Sousa SC: Homeobox genes: a molecular link between development and cancer. Pesqui Odontol Bras 2003, 17(1):94-8

7. Wellik DM: Hox genes and vertebrate axial pattern. Curr Top Dev Biol 2009, 88:257-78. 
8. Duboule D: The vertebrate limb: a model system to study the Hox/HOM gene network during development and evolution. Bioessays 1992, 14(6):375-84.

9. Cillo C, Faiella A, Cantile M, Boncinelli E: Homeobox genes and cancer. Exp Cell Res 1999, 248(1):1-9.

10. Armstrong SA, Staunton JE, Silverman LB, Pieters R, den Boer ML, Minden MD, Sallan SE, Lander ES, Golub TR, Korsmeyer SJ: MLL translocations specify a distinct gene expression profile that distinguishes a unique leukemia. Nat Genet 2002, 30(1):41-7.

11. Pineault N, Abramovich C, Ohta H, Humphries RK: Differential and common leukemogenic potentials of multiple NUP98-Hox fusion proteins alone or with Meis1. Mol Cell Biol 2004, 24(5):1907-17.

12. Hong JH, Lee JK, Park JJ, Lee NW, Lee KW, Na JY: Expression pattern of the class I homeobox genes in ovarian carcinoma. J Gynecol Oncol 2010, 21(1):29-37.

13. Hayashida T, Takahashi F, Chiba N, Brachtel E, Takahashi M, Godin-Heymann N, Gross KW, Vivanco MM, Wijendran V, Shioda T, Sgroi D, Donahoe PK, Maheswaran S: HOXB9, a gene overexpressed in breast cancer, promotes tumorigenicity and lung metastasis. Proc Natl Acad Sci USA 2010, 107(3):1100-5

14. Gray S, Pandha HS, Michael A, Middleton G, Morgan R: HOX genes in pancreatic development and cancer. JOP 2011, 12(3):216-9.

15. Caré A, Silvani A, Meccia E, Mattia G, Stoppacciaro A, Parmiani G, Peschle C, Colombo MP: HOXB7 constitutively activates basic fibroblast growth factor in melanomas. Mol Cell Biol 1996, 16(9):4842-51.

16. Caré A, Silvani A, Meccia E, Mattia G, Peschle C, Colombo MP: Transduction of the SkBr3 breast carcinoma cell line with the HOXB7 gene induces bFGF expression, increases cell proliferation and reduces growth factor dependence. Oncogene 1998, 16(25):3285-9.

17. Carè A, Felicetti F, Meccia E, Bottero L, Parenza M, Stoppacciaro A, Peschle C, Colombo MP: HOXB7: a key factor for tumor-associated angiogenic switch. Cancer Res 2001, 61(17):6532-9.

18. Bitu CC, Carrera M, Lopes MA, Kowalski LP, Soares FA, Coletta RD: HOXB7 expression is a prognostic factor for oral squamous cell carcinoma. Histopathology 2012, 60(4):662-5.

19. Liao WT, Jiang D, Yuan J, Cui YM, Shi XW, Chen CM, Bian XW, Deng YJ, Ding YQ: HOXB7 as a prognostic factor and mediator of colorectal cancer progression. Clin Cancer Res 2011, 17(11):3569-78.

20. Nguyen Kovochich A, Arensman M, Lay AR, Rao NP, Donahue T, Li X, French SW, Dawson DW: HOXB7 promotes invasion and predicts survival in pancreatic adenocarcinoma. Cancer 2013, 119(3):529-39.

21. Vandesompele J, De Preter K, Pattyn F, Poppe B, Van Roy N, De Paepe A, Speleman F: Accurate normalization of real-time quantitative RT-PCR data by geometric averaging of multiple internal control genes. Genome Biol 2002, 3(7):Research 0034.1-0034.11.

22. Andersen $C L$, Jensen $J$, Orntoft TF: Normalization of real-time quantitative reverse transcription-PCR data: a model-based variance estimation approach to identify genes suited for normalization, applied to bladder and colon cancer data sets. Cancer Res 2004, 64(15):5245-50.

23. Livak KJ, Schmittgen TD: Analysis of relative gene expression data using real- time quantitative PCR and the 22DDCT Method. Methods 2001, 25:402-408.

24. Abe A, Minaguchi T, Ochi H, Onuki M, Okada S, Matsumoto K, Satoh T, Oki A, Yoshikawa H: PIK3CA overexpression is a possible prognostic factor for favorable survival in ovarian clear cell carcinoma. Hum Pathol 2013, 44(2):199-207.

25. Lowry OH, Rosebrough NJ, Farr AL, Randall RJ: Protein measurement with the Folin phenol reagent. J Biol Chem 1951, 193(1):265-75.

26. Ferreira AK, Meneguelo R, Pereira A, Mendonça Filho O, Chierice GO, Maria DA: Anticancer effects of synthetic phosphoethanolamine on Ehrlich ascites tumor: an experimental study. Anticancer Res 2012, 32(1):95-104.

27. Vêncio RZ, Koide T: HTself: self-self based statistical test for low replication microarray studies. DNA Res 2005, 12(3):211-4.

28. Zhang B, Kirov S, Snoddy J: WebGestalt: an integrated system for exploring gene sets in various biological contexts. Nucleic Acids Res 2005, 33:W741-8.

29. Benjamini $Y$, Hochberg $Y$ : Controlling the false discovery rate: a practical and powerful approach to multiple testing. J R Statist Soc B 1995, 57(1):289-300.
30. Wang P, Henning SM, Heber D: Limitations of MTT and MTS-based assays for measurement of antiproliferative activity of green tea polyphenols. PLoS One 2010, 5(4):e10202.

31. Yunis AA, Arimura GK, Russin DJ: Human pancreatic carcinoma (MIA PaCa-2) in continuous culture: sensitivity to asparaginase. Int J Cancer 1977, 19:218-235.

32. Kyriazis AP, Kyriazis AA, Scarpelli DG, et al: Human pancreatic adenocarcinoma line Capan-1 in tissue culture and the nude mouse: morphologic, biologic, and biochemical characteristics. Am J Pathol 1982, 106:250-260.

33. Deer EL, González-Hernández J, Coursen JD, Shea JE, Ngatia J, Scaife CL, Firpo MA, Mulvihill SJ: Phenotype and genotype of pancreatic cancer cell lines. Pancreas 2010, 39(4):425-35.

34. Hyman E, Kauraniemi P, Hautaniemi S, Wolf M, Mousses S, Rozenblum E, Ringnér M, Sauter G, Monni O, Elkahloun A, Kallioniemi OP, Kallioniemi A Impact of DNA amplification on gene expression patterns in breast cancer. Cancer Res 2002, 62(21):6240-5.

35. Strathdee G, Holyoake TL, Sim A, Parker A, Oscier DG, Melo JV, Meyer S, Eden T, Dickinson AM, Mountford JC, Jorgensen HG, Soutar R, Brown R: Inactivation of HOXA genes by hypermethylation in myeloid and lymphoid malignancy is frequent and associated with poor prognosis. Clin Cancer Res 2007, 13(17):5048-55.

36. Wang H, Bei L, Shah CA, Horvath E, Eklund EA: HoxA10 influences protein ubiquitination by activating transcription of $\mathrm{ARIH} 2$, the gene encoding Triad1. J Biol Chem 2011, 286(19):16832-45.

37. Yu C, Zhang X, Sun G, Guo X, Li H, You Y, Jacobs JL, Gardner K, Yuan D, Xu Z, Du Q, Dai C, Qian Z, Jiang K, Zhu Y, Li QQ, Miao Y: RNA interference-mediated silencing of the polo-like kinase 1 gene enhances chemosensitivity to gemcitabine in pancreatic adenocarcinoma cells. J Cell Mol Med 2008, 12(6A):2334-49.

38. Réjiba S, Wack S, Aprahamian M, Hajri A: K-ras oncogene silencing strategy reduces tumor growth and enhances gemcitabine chemotherapy efficacy for pancreatic cancer treatment. Cancer Sci 2007, 98(7):1128-36.

doi:10.1186/1471-2407-13-451

Cite this article as: Chile et al:: HOXB7 mRNA is overexpressed in pancreatic ductal adenocarcinomas and its knockdown induces cell cycle arrest and apoptosis. BMC Cancer 2013 13:451.

\section{Submit your next manuscript to BioMed Central and take full advantage of:}

- Convenient online submission

- Thorough peer review

- No space constraints or color figure charges

- Immediate publication on acceptance

- Inclusion in PubMed, CAS, Scopus and Google Scholar

- Research which is freely available for redistribution 